\title{
A Lei no 11.645/2008 e os necessários diálogos entre histórias, culturas e artes indígenas na Educação Infantil
}

\begin{abstract}
Resumo:
Após mais de uma década da promulgação da Lei no 11.645/2008, observa-se principalmente na Educação Infantil, visões folclorizadas no ensino sobre a temática indígena. Para outra abordagem, partir de diálogos entre a História, a Antropologia e Artes realizamos o projeto pedagógico "Indígenas não têm lendas! Têm histórias, culturas e artes!", com uma turma de 20 crianças entre três a quatro anos de idade. Como estratégia pedagógica, rodas de conversas para contação de histórias, a partir de narrativas na literatura produzida por povos indígenas em Pernambuco e com várias atividades como exibição de documentários, construção de maquetes com massa de modelar. Observamos que as crianças perceberam a diversidade dos índios, os diferentes ambientes habitados, os conflitos entre indígenas e não indígenas, expressando indignação, empatia e solidariedade com os povos indígenas nas mobilizações por reconhecimento e garantia dos direitos.
\end{abstract}

\section{Palavras-chave:}

Indígenas. Educação Infantil. Interdisciplinaridade. Aprendizados.

\section{Resumen:}

Después de más de una década de la promulgación de la Ley n 11.645/2008, se observa principalmente en Educación Infantil, visiones folclóricas en la enseñanza sobre el tema indígena. Por otro enfoque, partiendo de los diálogos entre Historia, Antropología y Artes, llevamos a cabo el proyecto pedagógico "Indígenas não têm lendas! Têm histórias, culturas e artes!". Con un grupo de 20 niños de entre tres y cuatro años. Como estrategia pedagógica, círculos de conversación para la narración, basados en narrativas de la literatura producidas por pueblos indígenas en Pernambuco, y con diver-

\footnotetext{
* Professor titular de História da UFPE. Doutor em História (UNICAMP). Mestre em História (UFPE). Professor no Centro de Educação/Colégio de Aplicação - UFPE; docente no mestrado profissional em Ensino de História (ProfHistória/UFPE) e no Programa de Pós-Graduação em História na UFCG (Campina Grande - PB). E-mail: edson.edsilva@hotmail.com. ORCID iD: https:// orcid.org/0000-0002-6213-9927.

** Doutoranda em Antropologia (UFPE). Mestra em Educação Contemporânea (CAA/UFPE). Especialista em Culturas e História dos Povos Indígenas (UFRPE); professora na Educação Básica na Prefeitura do Recife; membro do Núcleo de Estudos e Pesquisas Históricas, Educação e Culturas (NEPHECs/UFRPE) e do Laboratório de Estudos sobre Ação Coletiva e Cultura - Universidade de Pernambuco. E-mail: dpenhasilva@gmail.com. ORCID iD: https://orcid.org/0000-0002-9248-2750.nares com esta modalidade de ensino. E-mail: benvenuti@ufrgs.br. ORCID iD: https://orcid.org/0000-0003-0243-0373.
} 
sas actividades como proyección de documentales, construcción de maquetas con plastilina. Observamos que los niños se dieron cuenta de la diversidad de los indígenas, los diferentes ambientes habitados, los conflictos entre indígenas y no indígenas, expresando indignación, empatía y solidaridad con los pueblos indígenas en las movilizaciones por el reconocimiento y garantía de derechos.

\section{Palabras-clave:}

Indígena. Educación Infantil. Interdisciplinariedad. Aprendizajes

\section{Introdução}

No atual cenário sociopolítico de negação, restrições e flagrantes desrespeitos aos direitos conquistados pelos povos indígenas e reconhecidos pela Constituição Federal promulgada em 1988 e em vigor, são fundamentais as discussões no campo da Educação não indígena. Mediante esse cenário, perguntamos: estudar sobre os indígenas não será reconhecê-los como contemporâneos e parte da nossa sociedade, ocupando diversos espaços, também os acadêmicos, produzindo conhecimentos científicos, questionando a história do Brasil, se afirmando como sujeitos históricos e de direitos? Pensando principalmente na Educação Básica e especificamente na Educação Infantil, onde em geral a temática indígena é abordada de forma folclórica, na maioria das vezes apenas no 19 de abril, o Dia do Índio, com a reprodução e muitos estereótipos. Esse nível de formação para crianças, é um espaço muito importante para contribuir com informações, promover discussões e aprendizados sobre o conhecimento crítico acerca das sociodiversidades e suscitar a solidariedade com os povos indígenas.

Buscando superar concepções folclorizadas, exóticas e romantizadas sobre "os índios", a partir de diálogos entre a História, a Antropologia e Artes realizamos o projeto pedagógico "Indígenas não têm lendas! Têm histórias, culturas e artes!", com uma turma de vinte crianças entre três a quatro anos de idade em uma creche municipal no Recife (PE). Como estratégia pedagógica, optamos por rodas de conversas para contação de histórias, a partir de narrativas na literatura produzida por povos indígenas em Pernambuco e com várias atividades como exibição de documentários, construção de maquetes com massa de modelar.

A Lei no 11.645/2008 completou 12 anos de promulgação com a alteração no artigo 26-A da Lei de Diretrizes e Bases da Educação Nacional (BRASIL, 1996), incluindo a obrigatoriedade do ensino sobre a história e as culturas dos povos indígenas no Brasil na Educação Básica (BRASIL, 2008). Regulamentada pelo Parecer CNE/CEB nº 14/2015 (BRASIL, 2016), ressaltando a necessidade do reconhecimento da atuação dessa parte da população na história do país e na contemporaneidade. Dessa forma, a pesquisa sobre a temática indígena em qualquer nível educacional não se constitui como conteúdo importante à formação de docentes para atuarem na efetivação da citada Lei? Como será possível sem formação a desconstrução dos estereótipos, preconceitos e equívocos historicamente institucionalizados nas práticas escolares, nos livros didáticos e na literatura infantil? Essas questões em geral estão muito distantes das discussões realizadas nas Secretarias de Educação.

Decorrida mais de uma década da promulgação da Lei no $11.645 / 2008$, observa-se avanços e desafios para a formação docente. Todavia, permanecem vários desafios para efetivação da Lei, como a ampliação da formação de professores seja nos curso de formação de professore, seja a formação continuada de docentes atuando na Educação Básica; a necessidade de maiores acervos nas bibliotecas escolares sobre as sociodiversidades indígenas, e até mesmo nas bibliotecas dos cursos de licenciaturas, e não somente na áreas das Ciências Humanas e Sociais, pois, o racismo estrutural e o desconhecimento generalizado sobre os povos indígenas é recorrente em todas as áreas do conhecimento (SILVA, 2019).

Embora, seja justo reconhecer que alguns avanços são visíveis no âmbito da formação docente, a exemplo da criação de novos componentes curriculares relacionados a temática indígena em alguns cursos de licenciaturas; a oferta de cursos gratuitos de extensão, especialização, mestrados profissionais e 
acadêmicos reconhecidos pelo Ministério da Educação (MEC) em grande parte propostos pela Secretaria de Educação Continuada, Alfabetização, Diversidade e Inclusão (SECADI); também observa-se algumas alterações nos livros didáticos de História na abordagem da temática indígena; a distribuição de kits com vídeos documentários nas instituições escolares públicas, embora ainda esteja aquém do proposto na referida Lei; a formação de Núcleos de Estudos Afro-Brasileiros e Indígenas (NEABIs); a produção de pesquisas no âmbito das pós-graduações em Educação e no mestrado profissional em Ensino de História (ProfHistória); publicações de várias coletâneas de textos discutindo sobre a temática, como as de Bergamaschi, Zen e Xavier (2012); Collet, Paladino e Russo (2013; Russo e Paladino (2016); Wittmann (2015); Silva e Silva (2016); Souza e Wittmann (2016); Andrade e Silva (2017), dentre outras.

Os avanços citados, em certa medida têm impactado as práticas escolares por meio dos/as docentes participantes nas formações específicas sobre a temática indígena ou étnico-racial. Por outro lado, a Lei $n^{\circ}$ 11.645/2008 ainda é desconhecida em boa parte de setores administrativos das Secretarias de Educação municipais e estaduais. Pesquisas apontaram que os docentes não são chamados a opinar sobre as necessidades formativas ou a formação continuada nem sempre corresponde às práticas pedagógicas dos docentes (PENNA; BELLO; JACOMINI, 2018). Dessa forma, são comuns os relatos de docentes atuando nas redes de ensino municipais, a exemplo de Porto Alegre, com lacunas na formação especifica e dificuldades para abordagem da temática indígena em sala de aula (BERGAMASCHI; GOMES, 2012, p. 58). Professores que pesquisam a temática indígena enfrentarem dificuldades burocráticas nos pedidos de afastamento para estudos nos cursos regulares, ou para participação em eventos. Nesses processos de pedidos de afastamentos, são considerados outros fatores gerais, todavia, como a Lei no $11.645 / 2008$ trata-se de uma legislação a ser efetivada, seria necessário esforços mais específicos nesse sentido. Diante dessa situação, docentes desejosos de qualificassem na temática indígena ou em qualquer outra, são forçados a frequentarem cursos com aulas nos finais de semana e as especializações ou mestrados profissionais, a maioria sem financiamentos de bolsas.

$\mathrm{O}$ afastamento para estudos esbarra em muito entraves burocráticos nas Secretarias Municipais de Educação, como evidenciado por um estudo (GEGLIO, 2015). Na Rede Municipal de Ensino no Recife também não vem sendo diferente. O prefeito por meio do Decreto no 30.360 (RECIFE, 2017) estabeleceu alguns critérios de licença para estudos. Dentre os quais: qualquer funcionário só poderia afastar-se por no máximo dois anos; se o curso ocorrer fora do município; se o projeto de pesquisa estabelecer relação direta com a prática profissional do requerente. Dessa forma, ainda no ano 2017 professores/as enfrentaram sérias dificuldades nos processos de afastamentos para participar de eventos científicos. Em alguns casos, depois de muitas peregrinações em várias gerências educacionais, eram liberados verbalmente, sendo publicadas as portarias correspondentes dois meses após a realização dos eventos. Caso ocorresse qualquer incidente ou acidente durante o período do evento, os/as docentes estariam desprotegidos juridicamente.

Mesmo frente as dificuldades mencionadas, sabendo da importância de ampliar os conhecimentos acerca da temática indígena, professores/as continuaram buscando uma formação de qualidade. Ainda que setores burocráticos da Educação desconheçam ou ignorem a dimensão da formação docente para atuar na efetivação da Lei $\mathrm{n}^{\circ}$ 11.645/2008. Sem apoio e incentivos oficiais, os/as professores/as e pesquisadores/ as sobre a temática étnico-racial buscam formação complementar específica nos eventos científicos de História, Educação, Antropologia, dentre outras áreas. Assistindo os debates, participando de minicursos, apresentando trabalhos e atividades afins. Assim, apreendendo teorias relevantes para as práticas pedagógicas sobre as diversidades étnico-raciais, sociocultural, sobretudo negras e indígenas, além de ampliar o olhar a respeito das situações cotidianas envolvendo não só a cultura escolar, mas também da sociedade que a constitui. Nessa perspectiva, reconhecendo a potencialidade de diálogos entre os diferentes campos de conhecimentos, a sala de aula torna-se num laboratório sociocultural à medida que se cria e se vivenciam situações evidenciando diferentes versões da história, e contatos com as sociodiversidades indígenas. 


\section{Aproximações entre histórias, culturas e artes dos povos indígenas na Educação Básica}

Durante os longos anos de atuação na Educação Básica, observamos que recorrentemente estar em sala de aula com crianças e adolescentes requer vivências de conteúdos curriculares incluindo temáticas referentes às diversidades socioculturais, sejam de classes sociais, gênero, sexualidade, geração ou étnico-raciais. Pois, os conflitos por oposição de gênero, as disputas de poder, o racismo, a homofobia, manifestam-se desde cedo na sociedade e na escola. Portanto, tratar sobre esses temas em sala de aula não é novidade nas práticas pedagógicas no cotidiano escolar.

Por outro lado quando e o quanto discutimos sobre a temática indígena? Em geral menos do que o necessário. Muito embora, sempre que oportuno mobilizamos conteúdos nesse sentido, mas, são ainda insuficientes para suprir o déficit historicamente existente nas práticas escolares. Sobretudo vivências para trocas de experiências entre professores/as, ou entre o alunado. A experiência pedagógica que discutiremos buscou suprir a citada lacuna. As vivências de ensino-aprendizagem, ocorreram em uma sala de aula do Grupo II, na Educação Infantil em uma creche da prefeitura da cidade do Recife, num bairro popular'1. A motivação foi a oposição às muitas práticas ainda vigentes de colegas docentes, como a ênfase nas datas comemorativas reforçando estereótipos, a exemplo do 19 de abril, o Dia do Índio, ou o 22 de agosto, o Dia do Folclore, ainda comumente festejadas nas instituições escolares nas redes públicas de ensino. Quando mais uma vez por ocasião do planejamento pedagógico coletivo, foram discutidos os conteúdos para o ensino especificamente para o mês de agosto, problematizamos junto as colegas as implicações do conceito de "folclore" atribuído as narrativas populares como "lendas", com significados apenas fantasiosos também para as expressões socioculturais indígenas. Em uma perspectiva pensando a produção e expressão de conhecimentos naturalmente hierarquizados, desvinculados das relações sociais de poder (FERNANDES, 1979).

Apesar dos argumentarmos sobre o quão ultrapassada a ideia das comemorações do "folclore" e mais ainda as práticas pedagógicas relacionadas à essa data, não foi possível demover as colegas. Mesmo questionando as implicações em classificar as "estórias", os relatos orais e a "cultura popular" como folclore. A partir do debate realizado, percebemos ser necessário estabelecer diálogos entre Educação, Antropologia e História argumentando sobre o sentido que o conceito "folclore" impactava no processo de validação dos conhecimentos populares, sempre vistos como inferiores. Nessa perspectiva, apresentamos uma contra proposta: realizar atividades buscando contrapor a folclorização da temática indígena, quando comumente é apresentada nas chamadas "lendas" contadas, encenadas e exaltadas no Dia do Folclore. Assim, recorremos a Teoria da Pesquisa-Ação, uma vez que esta poderia lhe possibilitar a análise da prática pedagógica enquanto ação em andamento, sendo avaliada e reformulada no processo de execução. Compreendendo que "[d]esenvolver pesquisa-ação é um movimento sistemático de questionamento, que exige coleta de informações sobre uma questão (problema de pesquisa), análise e desenvolvimento de planos práticos para implementar mudanças efetivas" (MALLMANN, 2015, p. 83).

Refletindo a partir da questão: como desfolclorizar as narrativas sobre os povos indígenas naquela ocasião específica? Nesse sentido, elaboramos o projeto pedagógico "Indígenas não têm lendas! Têm histórias, culturas e artes!”, inspirado nos diálogos entre a Educação, a Antropologia e a História executado com uma turma do Grupo III na Educação Infantil, com vinte crianças entre três a quatro anos de idade, com a mediação docente e mais dois auxiliares permanentes. Como estratégia pedagógica predominou a prática de contação de histórias sobre os povos indígenas em Pernambuco, seguida de várias atividades durante o período de realização do projeto. Partes dessas atividades serão apresentadas e discutidas a seguir. Possibilitando visualizar o planejamento geral, incluindo o conjunto dos subsídios pedagógicos mobilizados nessa vivência.

Foi priorizada a estratégia didática da contação de história, fazendo uso da produção literária e de vídeos-documentários, listados no final do presente texto, com narrativas sobre cada povo indígena em

1. Por razões éticas para preservar as pessoas e não tendo autorização legal, foi omitido o nome do estabelecimento escolar. 
Pernambuco, em grande parte, de autoria ou coautoria dos próprios indígenas; associando as histórias aos conteúdos da produção artística nos artefatos da cultura material e imaterial daqueles povos. $\mathrm{O}$ uso desses subsídios foi uma estratégia para visibilizar e valorizar o protagonismo e a produção dos indígenas, apresentados como sujeitos sociopolíticos na contemporaneidade. Dentre os símbolos da cultura material e imaterial foram exploradas diversas imagens de espaços sagrados e rituais religiosos; além das peças ritualísticas como a maraca, a barretina ${ }^{2}$, colares, cocares, saiotes de fibras vegetais (tacó); e utensílios cotidianos como cestos, vassoura, bolsa (ayó), dentre outros.

Nas atividades realizadas, a multidisciplinaridade foi contemplada, quando por meio da contação de histórias, simultaneamente foi possível mobilizar conteúdos curriculares em todos os eixos temáticos nas diversas áreas: Ciências Humanas e suas Tecnologias; Ciências da Natureza, Matemática e suas Tecnologias; e Linguagens, Códigos e suas Tecnologias. Assim, compreendemos que a prática de contação de histórias contribui efetivamente para exercitar leituras do mundo, sobretudo, pensando em uma perspectiva antropológica. Uma vez que a Antropologia, historicamente, teve como objeto de estudo a Cultura e dentre os aspectos culturais, a Educação, logo, o simples ato de contar uma história pode ser entendido como um ato antropológico. Isso porque "[q]uando você conta a história para a criança já faz parte da própria educação, de sua própria formação como ser social e ser biopsíquico, o anthropos. Faz parte de seu olhar epistemológico e aí estão embutidos os valores, as crenças, a visão de mundo de uma determinada cultura" (VIEIRA; BADIA, 2015, p. 258).

Nesse sentido, a prática de contação de histórias como fio condutor do citado projeto favoreceu a aproximação das crianças com a história e as expressões socioculturais dos vários povos indígenas em Pernambuco. Sobretudo, ao adotarmos como subsídio básico o livro Meu povo conta (PROFESSORES E PROFESSORAS INDÍGENAS EM PERNAMBUCO, 2006) com narrativas históricas, contos e mitos dos povos indígenas Atikum, Kambiwá, Kapinawá, Pankará, Pankararu, Pipipã, Truká, e Xukuru do Ororubá. Embora contenha as narrativas de apenas oito povos, quando atualmente são mais de 14 grupos indígenas autodeclarados em Pernambuco, esse livro, ainda pode ser uma referência para subsidiar a atividade pedagógica na Educação Infantil sobre os povos indígenas no estado. Sendo complementado com as demais produções individuais de cada povo.

Enfim, por que contação de histórias e não de "lendas"? As definições conceituais acerca do gênero literário chamado "lendas" são diversas, geralmente, encontradas nos dicionários da língua portuguesa, nos textos sobre o folclore brasileiro, nas obras de literatura infantil. Embora, todas, basicamente, remetam à ideia de narrativas populares, suscitando suspeitas sobre a veracidade (BONIN, 2009, p. 102). Consultamos os dicionários Houaiss e o Aurélio, distribuídos na Rede Municipal de Ensino do Recife, onde existem as seguintes definições:

Lenda 1- Mesmo que legenda ('vida de santo'); 2- Narrativa de caráter maravilhoso em que há um fato histórico centralizado em torno de algum herói popular (revolucionário, santo, guerreiro), se amplifica e se transforma sob o efeito da evocação poética ou imaginação popular; 3- Narrativa ou crendice acerca de seres maravilhosos e encantatórios, de origem humana ou não, existente no imaginário popular; 4- Tradição popular - uma cultura com raízes na lenda e não na ciência. (HOUAISS; VILAR, 2001, p. 1740).

Lenda 1- Tradição popular; 2- Narração de caráter maravilhoso, em que fatos históricos são deformados pela imaginação popular ou pela invenção poética. (FERREIRA, 2001, p. 422).

Observa-se que as "lendas" podem ser entendidas como narrativas populares distorcidas, exageradas, ou que inspiram suspeitas em torno das situações narradas. Assim, quando chamamos de "lendas" as narrativas dos ou sobre os povos indígenas ou de outros grupos de "tradição" oral, a história, os relatos

2. Adereço para a cabeça, de palha de coqueiro ou palmeira Ouricuri, árvore típica do semiárido nordestino. Em formato de cone, usado com significados religioso ou político por alguns povos indígenas, como os Xukuru do Ororubá (Pesqueira e Poção - PE) e povos da grande família Pankararu em Pernambuco e Alagoas. 
e mitos desses povos são reduzidas à folclorização, não são validadas como conhecimentos sócio-históricos. Sendo importante considerar ainda os significados das práticas escolares comemorativas, ditas especiais, que difundem essa ideia:

[...] a pluralidade cultural de grupos étnicos, sociais ou culturais necessita ser pensada como matéria-prima da aprendizagem, porém nunca como conteúdo de dias especiais, datas comemorativas ou momentos determinados em sala de aula. Fazer isso é congelar a cultura, reificá-la, transformá-la em recurso de folclorização, e como tal acentuar as diferenças. (GUSMÃO, 2003, p. 95).

Na citação acima foi chamada a atenção para que embora seja imprescindível reconhecer e valorizar as diferenças socioculturais, étnico-raciais, essa diferenciação não pode servir como reprodução de estereótipos, discriminação e exclusão. Sendo, portanto, muito importante não permitir que as diferenças se transformem em desigualdades, e sim, possibilidades de trocas, comunicações e equidade entre sujeitos diferentes. Reconhecendo a heterogeneidade na qual se constitui a sociedade, e que historicamente foi negada pela escola. Sendo indispensável pensá-la sempre como um espaço plural (GUSMÃO, 2003).

Refletindo a partir dessa abordagem, no âmbito da temática indígena observando as imagens e narrativas construídas ao longo do tempo sobre os povos indígenas, compreende-se que por vezes foram pautadas pela concepção de diversidade, mas em uma perspectiva essencialista, evidenciando os indígenas apenas culturalmente diferentes da sociedade brasileira. Consequentemente, reproduzindo o discurso sobre uma suposta identidade indígena pensada e narrada a parir da unificação da diferença pautada em visões etnocêntricas (BONIN, 2007). A diversidade cultural nesse sentido, unificando, homogeneizando, nomeando quem é indígena e excluindo o que difere de certo padrão sociocultural hegemônico.

De forma que, a inclusão ou exclusão de critérios para nomear quem é ou não indígena nas "lendas", implica em adjetivações sobre os modos de ser e viver desses povos, visto como grupos distintos, distantes no tempo e geograficamente, representados como sociedades de costumes "primitivos", "selvagens", "exóticos" e míticos. E também pensados como pessoas "incapazes" intelectualmente e vistos como "seres infantis". Adjetivações contrárias à Constituição Federal (BRASIL, 1988) em vigor, quando reconheceu dentre os direitos fundamentais dos povos indígenas, a autonomia intelectual, para se auto representar como cidadãos brasileiros sem com isso ter que omitir ou negar a identidade étnica. Assim, suscitando mudanças de paradigmas nas abordagens da História, mas também na Antropologia, na Educação, e sobretudo, na Literatura, tratando-se dos conteúdos socioculturais dos povos indígenas.

No campos da História, foram revistas as narrativas anunciando a inevitável integração dos índios à sociedade nacional, somando-se à ideia de uma suposta extinção; e evidenciando os indígenas não apenas figurantes, mas protagonistas na História (ALMEIDA, 2010). Para a Antropologia implicou pensar as novas reconfigurações das identidades socioculturais indígenas, a partir dos processos de redemocratização do país e a efervescência das mobilizações políticas em defesa dos direitos conquistados, sem reducionismo ou generalizações (LUCIANO, 2006). Para a Educação, quando na formulação da nova Lei de Diretrizes e Base da Educação Nacional e demais documentos curriculares subsequentes, significou considerar as novas abordagens históricas e antropológicas sobre os povos indígenas, repensando as práticas escolares (SILVA, 2015). No campo da Literatura, surgiram diversas produções indígenas, geralmente destinadas ao ensino específico e diferenciado nos territórios indígenas, embora, muitas obras encontrem-se disponíveis na internet, sendo possível o acesso e uso nos espaços de leituras e salas nas escolas de Educação Básica em geral. 


\section{Contação de histórias, contos e mitos dos povos indígenas em Pernambuco}

A execução do projeto “Indígenas não têm lendas! Têm histórias, culturas e artes!" iniciou com uma história narrada por professores e professoras indígenas. $\mathrm{Na}$ ocasião, onde todos na sala de aula foram posicionados em forma de círculo ${ }^{3}$, com adultos e crianças sentados no chão; a professora de posse do livro Meu povo conta, folheando-o para que as crianças pudessem visualizar as imagens e ao mesmo tempo eram lidos os títulos das histórias. Foi escolhido o relato "A cobra da baixa verde", narrado pelo povo Pankará. Em seguida, a professora dispôs fichas/cartões ${ }^{4}$ como apoio pedagógico, onde constavam imagens e nomes dos grupos indígenas em Pernambuco. Mostrando às crianças a imagem correspondente ao povo Pankará. A ficha/cartão circulou entre as crianças, durante um curto espaço de tempo, quando então começamos a contação de história.

Devido a faixa etária das crianças, quando encontram-se ainda na fase do concreto, o que mais lhes chamou atenção na história narrada sobre o povo Pankará era a ideia sobre o tamanho da cobra e não a cobra como um ser mítico, mágico, ou coisa parecida. Mesmo porque, não havia nenhuma ilustração gráfica do animal, apenas narrativas sobre o rastro. Então, conversou-se sobre as supostas características físicas daquele animal, a forma, o tamanho, os movimentos e o imaginário indígena sobre aquele ser mítico. Em seguida foi distribuído massa de modelar para todas as crianças e sugerido que cada uma modelasse a figura de uma cobra. Na sequência pedimos que unissem todas e formassem uma só.

Após a cobra construída coletivamente ser concluída, as crianças puderam observá-la. Em seguida foram orientadas à transportá-la para uma base de cartolina, fixando-a de forma a expressar os movimentos em linhas curvas. Como apresentado nas imagens (Figura 1). Voltamos à roda de contação de história para continuar discutindo sobre a cobra, retomando alguns aspectos enfatizados na história envolvendo o animal como personagem. A professora chamou a atenção das criança sobre a importância do trabalho em equipe remetendo à força da organização política dos povos indígenas em Pernambuco.

Figura 1 - Produção coletiva de uma das personagens na história "A cobra da baixa verde”

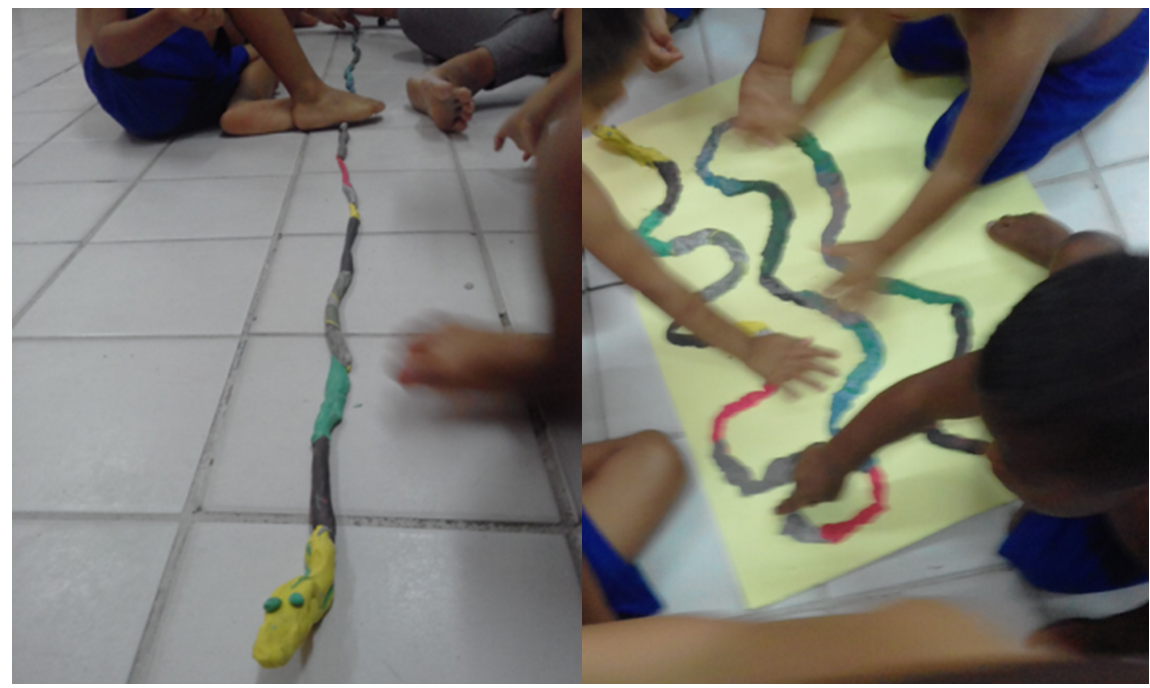

Fonte: Acervo dos autores.

Possivelmente a ideia de união e coletividade dos povos indígenas naquele momento inicial não significou muito para as crianças. Somente após dias consecutivos de atividades sobre a temática, mobilizando várias estratégias, a exemplo do manuseio de outros livros e materiais impressos, a exibição de diferentes

3. Nomeamos essa dinâmica como "roda de contação de história".

4. O uso das fichas/cartões foi constante em todos momentos. Confeccionadas previamente em pedaços de cartolina guache com aproximadamente $15 \mathrm{~cm}$ em cada lateral. Cada uma com dados sobre um povo indígena e ilustrações em ambos os lados. Em um lado, na parte superior constava o nome do povo em letras maiúsculas e no centro uma fotografia de um ou mais indivíduos de cada grupo indígena; do outro lado, uma paisagem do Território indígena. 
vídeos-documentários e a apreciação dos artefatos materiais produzidos pelos povos indígenas, como observado na Figura 2, as crianças foram compreendendo as relações entre os aspectos físicos e ambientais e as atividades para o consumo; as expressões socioculturais; as artes manuais; e sobretudo, as disputas pela posse dos territórios por meio das mobilizações coletivas dos indígenas.

Figura 2 - Roda de leitura de imagem de artefatos indígenas

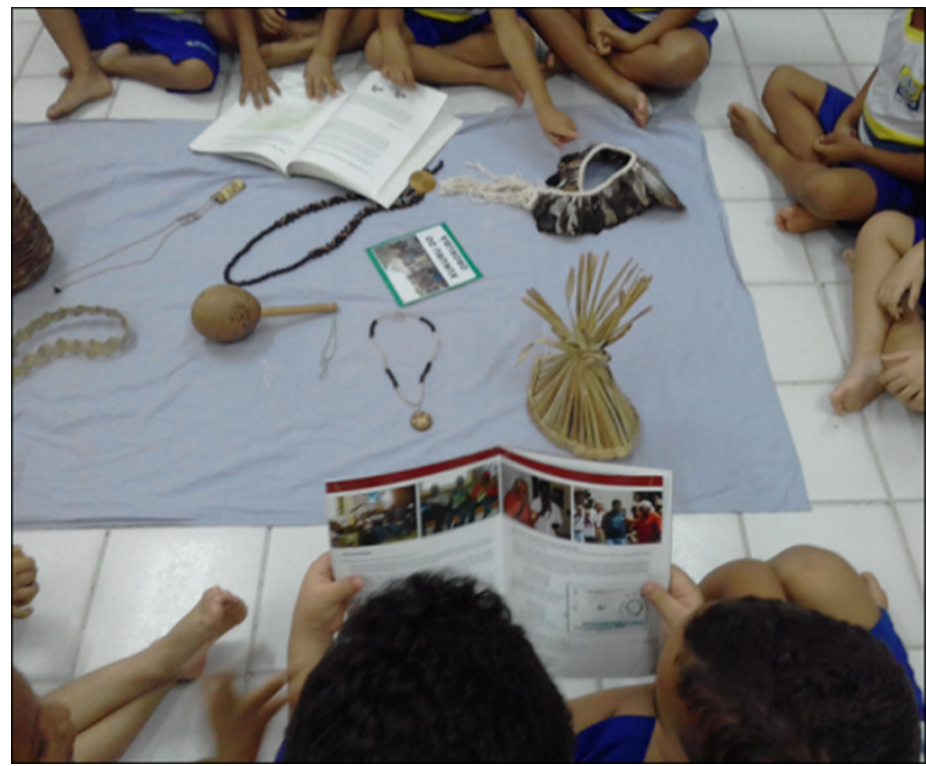

Fonte: Acervo dos autores.

A Figura 2 apresenta um dos momentos em que foi vivenciada com as crianças a história narrada pelo povo Xukuru do Ororubá. Além da leitura de imagens impressas também tiveram acesso a vários artefatos da cultura material e imaterial daquele povo. E com a exibição de parte do videodocumentário Xicão Xukuru (1998), uma narrativa histórica, denunciando as violências e perseguições aos indígenas no período da colonização e na contemporaneidade com o assassinato do Cacique "Xicão" a mando dos fazendeiros invasores nas terras indígenas; enfatizando também a dimensão sagrada da Natureza pelos indígenas, sobretudo, as referências à água como "o sangue da Terra".

A água é um recurso natural muito citado nas histórias narradas pelos povos indígenas em Pernambuco habitantes no Semiárido onde ocorrem longas estiagens ou secas prolongadas. Em muitas situações a água é relacionada com o sagrado. Como também envolve as disputas com os não indígenas pelo uso das poucas fontes de água no semiárido. A água como um aspecto comum nas narrativas indígenas, não havia impactado tanto a percepção das crianças em relação a diversidade sociocultural indígena em Pernambuco, até o momento da contação da história sobre o povo Truká, onde nas narrativas de aspectos socioculturais foram mais visíveis as diferenças em relação a outros povos.

Até então, as histórias contadas apresentavam como características comuns os relatos sobre os impactos da colonização, os cenários com serras, pedras, matas, seres encantados, as práticas da agricultura e pecuária como meio de vida e resistência. Embora as narrativas Truká tivessem algumas semelhanças, chamou atenção das crianças a relação com o Rio São Francisco, o habitar nas ilhas, navegar em canoas, pescar, as crenças em entidades religiosas relacionadas às águas. Esses aspectos suscitaram novas perguntas das crianças, a exemplo de: Onde está a serra e a mata? Não tem espíritos da mata? Eles comem só peixes? Vão para a escola de barco? Dentre outros questionamentos curiosos.

Após conversar sobre os temas das perguntas, a professora sugeriu a escolha de uma situação narrada no livro do povo Truká, para a releitura a partir da produção de uma maquete com massa de modelar. A situação selecionada pelas crianças foi a ilustração referente ao aspecto geográfico do território Truká, as ilhas no rio São Francisco. A medida que as crianças decidiram o que queriam modelar, foram agrupadas conforme os elementos para compor a maquete: a base (o rio e as ilhas), as pessoas, as edificações, a vege- 
tação e os animais. Com o esboço do desenho da base elaborado pela professora, logo foi preenchido pelas crianças responsáveis por essa parte. Paralelo a isto, as duas pessoas auxiliares orientavam as outras crianças a confeccionarem os outros elementos da paisagem. Assim, enquanto a equipe responsável pela base da maquete, a produção do rio e das ilhas, concluiu essa parte, as demais equipes foram compondo o restante do cenário. Resultando no exposto na Figura 3:

Figura 3 - Produção coletiva sobre a Ilha de Assunção, Cabrobó - povo Truká

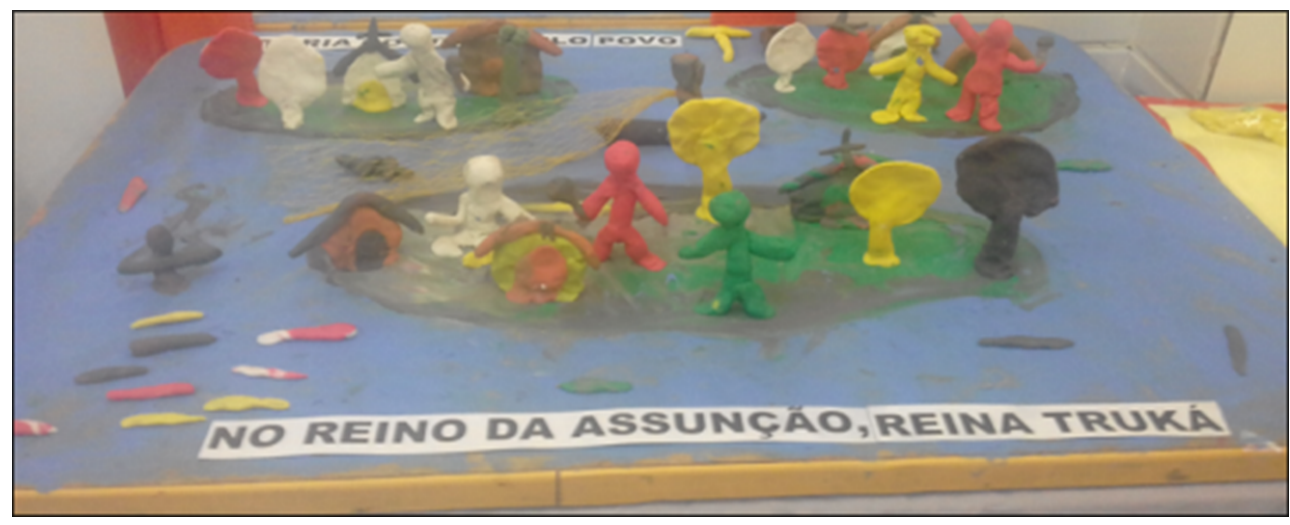

Fonte: Acervo dos autores.

Diferentemente dos demais territórios indígenas narrados anteriormente, citando as raras fontes de água, o território do povo Truká demarcava uma outra ideia: a água como grande parte desse território. $\mathrm{Na}$ maquete, em primeiro plano na parte de baixo estão os peixes coloridos; um pouco acima no mesmo lado o "Nego d’Água” uma entidade religiosa citada pelos indígenas. No centro está a Ilha da Assunção, no último plano acima as outras duas ilhas, todas constituídas por vegetação, moradias, escolas, igreja e pessoas. No meio do rio entre as ilhas, uma pessoa numa pequena embarcação pescando com uma rede amarela. As imagens do rio São Francisco, peixes e embarcações são evidenciadas ao longo do livro No Reino de Assunção reina Truká (SANTO et al., 2007), demarcando o jeito de ser e estar no universo indígena Truká.

De forma geral, as imagens com pinturas corporais, indumentárias ritualísticas, as práticas de pesca e caça marcaram bastante o imaginário das crianças dificultando o reconhecimento de indivíduos indígenas que não apresentavam sinais diacríticos tão evidentes. A esse respeito ocorreram duas situações. A primeira, quando recebemos a visita de uma jovem pankararu, estudante de Veterinária, a quem foi sugerida propositalmente apresentasse às crianças vestida com o tacó ${ }^{5}$, cocar de penas e a maraca. E em outra ocasião, quando uma jovem Xukuru do Ororubá, estudante de Enfermagem, esteve na sala de aula sem nenhum artefato material que imediatamente indicasse a identidade étnica. Na primeira situação, a jovem pankararu diferenciava dos aspectos físicos mais comuns daquele povo, pois tinha a pele branca e cabelos artificialmente colorido avermelhado. Não fossem os artefatos com os quais se apresentou, possivelmente as crianças não a reconheceriam como pankararu. Entretanto, foi bem aceita pelas crianças e adultos como membro de um povo indígena.

Em contrapartida, a jovem Xukuru do Ororubá era a cor de pele negroide, cabelos longos, lisos e pretos, o estereótipo indígena comumente visto na literatura infantil em geral. Mesmo após apresentá-la, inclusive anunciando o nome do seu povo, por não portar nenhum artefato da cultura material visível, as crianças não a reconheceram como indígena. E muito menos como Xukuru do Ororubá! E logo exclamaram: "Ela não é Xukuru! Ela não tem aquela coisa na cabeça”. Ao serem perguntadas “Qual coisa? O cocar?”, responderam: “Não! Aquela coisa de palha!”. Compreendeu-se que as crianças se referiam à barretina usada pelo povo Xukuru do Ororubá. Por um lado foi frustrante ouvir essas afirmações depois de todas as tentativas de desconstrução dos estereótipos, mas, por outro lado, foi gratificante perceber que as crianças conseguiam associar o nome do povo Xukuru do Ororubá ao uso do citado artefato. E assim o diferenciando dos povos

5. Saiote de fibra de Caroá, árvore típica do semiárido nordestino, usado pelos indígenas em rituais. 
indígenas no Norte ou Centro-Oeste comumente usando cocares de penas coloridas. Ainda que os Xukuru do Ororubá também usem cocares, todavia é mais recorrente a barretina.

\section{Considerações finais}

Depois de mais de uma década de promulgação da Lei no 11.645/2008 determinando na Educação Básica o ensino sobre a história e culturas dos povos indígenas, é necessário verificar quais mudanças ocorreram nas práticas pedagógicas, especificamente na Educação Infantil, a partir da citada legislação. Observando docentes em sala nesse nível de ensino, constatamos que em muito continuam ações anteriores a citada Lei, vinculando as discussões acerca do assunto apenas ao Dia do Índio ou ao Dia do Folclore. E dessa forma reproduzindo desinformações, equívocos e imagens caricatas sobre os povos indígenas.

Nesse texto apresentamos e analisamos brevemente, uma experiência de ensino sobre a temática indígena com uma turma de crianças na Educação Infantil. Como estratégia pedagógica com rodas de conversas para contação de histórias, a partir de narrativas na literatura produzida por povos indígenas em Pernambuco e com várias atividades como exibição de documentários, construção de maquetes com massa de modelar. Após as atividades, observamos que as crianças perceberam as relações de poder, os conflitos entre indígenas e não indígenas, as manifestações políticas, as expressões artísticas e religiosas na medida em que lhe foram apresentadas as semelhanças e as diferenças entre os povos indígenas em Pernambuco, relacionadas ao ambiente e aos processos históricos vivenciados por esses povos. Em uma experiência muito significativa no que se refere ao reconhecimento desses povos como grupos sociais diferenciados entre si e da nossa sociedade.

Enfim, as crianças compreenderam que historicamente os povos indígenas foram perseguidos, tiveram as terras usurpadas, as expressões socioculturais modificadas, mas de várias formas resistem; e as crianças criaram uma empatia pelos povos indígenas, expressando indignação e sentimento de solidariedade quando nas narrativas impressas ou nos videodocumentários viam alguma cena de agressão física aos indígenas. A exemplo da cena no vídeo Demarcação já! (2017), onde apresentou a ostensiva tropa de choque da polícia contra os índios numa mobilização em Brasília (DF).

O processo de execução do projeto culminou na exposição das produções da turma junto aos subsídios utilizados, o acervo literário, artefatos materiais e imateriais indígenas, como também recebendo a visita das outras turmas da creche. Somado às duas situações com os contatos direto entre as crianças e as duas jovens indígenas, evidenciou na prática que foi possível desfolclorizar a temática indígena naquelas ocasiões específicas. Isso ocorreu por meio da aproximação direta com as narrativas, produção artística e sociocultural dos povos indígenas. Embora saibamos que a elaboração, execução de um projeto e as vivências de um processo como o citado não surge de imediato, mas após um bom tempo de dedicação e estudos sobre a temática indígenas.

Sendo necessário, portanto, vontade política dos gestores públicos, situação rara nos dias atuais, investimentos em subsídios pedagógicos, na formação docente e compromisso desses/as na construção de uma sociedade igualitária, justa que reconheça a importância das sociodiversidades a partir dos povos indígenas. Buscando ainda, contribuir para uma formação crítica na Educação Infantil, desde a tenra idade, no atual contexto de retrocessos sociopolíticos, perseguições, descasos e abandono com a pandemia do Covid-19, enfrentados pelos povos indígenas no Brasil.

\section{Referências}

ALMEIDA, Maria Regina Celestino. Os índios na História do Brasil. Rio de Janeiro: FGV, 2010.

ANDRADE, Juliana Alves de; SILVA, Tarcísio Augusto Alves da (org.) O ensino da temática indígena: subsídios didáticos para o estudo das sociodiversidades indígenas. Recife: Edições Rascunhos, 2017. 
BONIN, Iara Tatiana. E por falar em povos indígenas: quais as narrativas contam em práticas pedagógicas. 2007. Tese (Doutorado em Educação) - Faculdade de Educação, Universidade Federal do Rio Grande do Sul, Porto Alegre, 2007.

BONIN, Iara Tatiana. Cenas da vida indígena na literatura que chega às escolas. Série Estudos: Periódico do Mestrado em Educação da UCDB, Campo Grande, n. 27, p. 97-109, jan./jun. 2009.

BRASIL. [Constituição (1988)]. Constituição da República Federativa do Brasil. Brasília, DF: Presidência da República [2020].

BRASIL. Lei no 9.394, de 20 de dezembro de 1996. Estabelece as diretrizes e bases da educação nacional. Diário Oficial da União: seção 1, Brasília, DF, p, 27833, 23 dez. 1996. Disponível em: http://www.planalto.gov.br/ccivil_03/leis/19394. htm. Acesso em: 6 maio 2018.

BRASIL. Lei no 11.645, de 10 março de 2008. Altera a Lei $\mathrm{n}^{\circ}$ 9.394, de 20 de dezembro de 1996, modificada pela Lei $\mathrm{n}^{\circ}$ 10.639, de 9 de janeiro de 2003, que estabelece as diretrizes e bases da educação nacional, para incluir no currículo oficial da rede de ensino a obrigatoriedade da temática "História e Cultura Afro-Brasileira e Indígena". Diário Oficial da União: seção 1, Brasília, DF, p. 1, 11 mar. 2008.

BRASIL. Ministério da Educação. Parecer CNE/CEB nº 14/2015. Diretrizes Operacionais para a implementação do ensino da história e das culturas dos povos indígena na Educação Básica, em decorrência da Lei no 11.645/2008. Diário Oficial da União: seção 1, Brasília, DF, p. 43, 18 abr. 2016. Disponível em: http://portal.mec.gov.br/index.php?option= com_docman\&view=download\&alias=27591-pareceres-da-camara-de-educacao-basica-14-2015-pdf\&Itemid=30192. Acesso em: 21 mar. 2019.

BERGAMASCHI, Maria Aparecida; ZEN, Maria Isabel Habckost Dalla; XAVIER, Maria Luísa Merino de Freitas (org.). Povos indígenas \& Educação. 2. ed. Porto Alegre: Mediação, 2012.

BERGAMASCHI, Maria Aparecida; GOMES, Luana Barth. A temática indígena na escola: ensaios de educação intercultural. Currículo sem Fronteiras, [S. l.], v. 12, n. 1, p. 53-69, jan./abr. 2012

COLLET, Célia; PALADINO, Mariana; RUSSO, Kely. Quebrando preconceitos: subsídios para o ensino das culturas e histórias dos povos indígenas. Rio de Janeiro: Contra Capa, Laced, 2013.

DEMARCAÇÃO já! Direção: André Vilela D’Elia. Compositores: Carlos Rennó e Chico César. Intérpretes: Ney Matogrosso et al. São Paulo: Cinedelia, 2017. 1 vídeo (15 min).

FERNANDES, Florestan. Folclore e mudança social na cidade de São Paulo. 2. ed. Petrópolis: Vozes, 1979.

FERREIRA, Aurélio B. de Holanda. Mini-aurélio Século XXI Escolar: o minidicionário da Língua Portuguesa. 4. ed. revisada e ampliada. Rio de Janeiro: Nova Fronteira, 2001.

GEGLIO, Paulo César. Políticas públicas de formação continuada para professores: um estudo de cursos realizados a partir de propostas licitatórias. Ensaio: Avaliação e Políticas Públicas em Educação, Rio de Janeiro, v. 23, n. 86, p. 231-257, jan./mar. 2015.

HOUAISS, Antônio; VILAR, Mauro de Salles. Dicionário Houaiss da Língua Portuguesa. Rio de Janeiro: Objetiva, 2001.

GUSMÃO, Neuza Maria Mendes de. Os desafios da diversidade na escola. In: GUSMÃO, Neuza Maria Mendes de. Diversidade, cultura e educação: olhares cruzados. São Paulo: Biruta, 2003. p. 83-105.

LUCIANO, Gersem dos Santos. O índio brasileiro: o que você precisa saber sobre os povos indígenas no Brasil de hoje. Brasília, DF: SECAD; Rio de Janeiro: LACED, 2006. (Coleção Educação para Todos).

MALLMANN, Elena M. Pesquisa-ação educacional: preocupação temática, análise e interpretação crítico-reflexiva. Cadernos de Pesquisa, São Paulo, v. 45, n. 155, p. 76-98, jan./mar. 2015.

PENNA, Marieta Gouvea de Oliveira; BELLO, Isabel Melero; JACOMINI, Márcia Aparecida. Análise de teses e dissertações sobre políticas de formação continuada de professores da Educação Básica (2000-2010). Revista Olh@res, São Paulo, v. 6, n. 2, p. 35-56, nov. 2018.

PROFESSORES E PROFESSORAS INDÍGENAS EM PERNAMBUCO. Meu povo conta. 2. ed. Belo Horizonte: Centro de Cultura Luiz Freire, 2006.

RECIFE. Prefeitura Municipal. Decreto n 30.360, de 22 de março de 2017. Regulamenta o afastamento remunerado, a pedido, dos servidores públicos municipais efetivos da administração direta e indireta do poder executivo municipal, para fins de participação em cursos de pós-graduação lato sensu e stricto sensu. Diário Oficial do Município do Recife:, Poder Executivo, Recife, ano 46, n. 35, p. 3, 23 mar. 2017.

RUSSO, Kelly; PALADINO, Mariana. Ciências, tecnologias, artes, e povos indígenas no Brasil: subsídios e debates a partir da Lei 11.645/2008. Rio de Janeiro: Garamond, 2016. 
SANTOS, Adriana Maria et al. No Reino de Assunção reina Truká. Belo Horizonte: FALE/UFMG: SECAD/MEC, 2007.

SILVA, Edson. Índios: pensando o ensino e questionando as práticas pedagógicas. Instrumento: Revista de Estudo e Pesquisa em Educação, Juiz de Fora, v. 21, n. 2, p. 168-186, jul./dez. 2019.

SILVA, Edson; SILVA, Maria da Penha da (org.). A temática indígenas na sala de aula: reflexões para o ensino a partir da Lei 11.645/2008. 2. ed. Recife: Edufpe, 2016.

SILVA, Maria da Penha da. A temática indígena nos anos iniciais do ensino fundamental: um estudo das práticas curriculares docentes em Pesqueira-PE. 2015. Dissertação (Mestrado em Educação) - Centro Acadêmico do Agreste, Universidade Federal de Pernambuco, Caruaru, 2015.

SOUZA, Fábio Feltrin de; WITTMANN, Luisa Tombini (org.). Protagonismo indígena na História. Tubarão: UFFS, 2016. (Coleção Educação para as relações étnico-raciais, v. 4).

VIEIRA, Karina Augusta Limonta; BADIA, Denis Domeneghetti. O ensino de Antropologia nos cursos de Pedagogia: caminhos para a diversidade. Práxis Educacional, Vitória da Conquista, v. 11, n. 20, p. 247-269, set./dez. 2015.

WITTMANN. Luisa Tombini (org.). Ensino (d)e História Indígena. Belo Horizonte: Autêntica, 2015.

XICÃO Xukuru. Direção: Nilton Pereira. Edição: Nilton Pereira e Didier Bertrand. Áudio: Uirá Ferreira e Bob Silva. Olinda: TV VIVA/CCLF, 1998. 1 vídeo (20 min 38 s).

\section{Outras obras utilizadas durante a execução do projeto}

ALMEIDA, Alfredo Wagner Berno de et al. Nova Cartografia Social dos Povos e Comunidades Tradicionais do Brasil: povos indígenas em Pernambuco. Manaus: UEA Edições, 2010.

ALMEIDA, Eliene Amorim (org.). Xukuru: filhos da mãe natureza - uma história de resistência e luta. Olinda: Centro de Cultura Luiz Freire, 1997.

IHIATO: narrativas dos anciões Fulni-ô. Direção: Elvis Ferreira. Brasília, DF: FMT/MinC, 2015. 1 vídeo (98 min).

KAPINAWÁ: meu povo conta. Direção: Nilton Pereira. Olinda: TV VIVA/CCLF, 2007. 1 vídeo (51 min 59 s).

PROFESSORES E PROFESSORAS INDÍGENAS EM PERNAMBUCO. Nosso povo, nossa terra: contando e escrevendo suas histórias. Recife: SEDUC/PE, 2000.

Data de submissão: 22/06/2020

Data de aceite: 25/07/2020 